\section{Extreme Isotopic Compositions of Carbon and Redox Processes}

IN the past ten years, carbonate phases highly enriched in ${ }^{13} \mathrm{C}$ have been found in the carbonate phases of carbonaceous chondrites $^{1-3}$-in some of these enrichment of ${ }^{13} \mathrm{C}$ has ranged from +40 to $+70 \%$ compared with the PDB standard. An enrichment of $25 \%$ in ${ }^{13} \mathrm{C}$ has also been reported for the carbonate phase of a kimberlitic dike ${ }^{4}$. Several explanations of these enrichments have been put forward, but none of them appears to be completely adequate ${ }^{5,6}$. This communication is an attempt to show that high enrichments can be accounted for by Rayleigh distillation involving oxidized and reduced forms of carbon.

In the presence of mineral assemblages resembling the systems we are dealing with, a decrease in temperature causes the transformation of $\mathrm{CO}_{2}$, stable at high temperatures, to reduced forms of carbon such as $\mathrm{CH}_{4}$ (ref. 7). Also, large equilibrium fractionations occur, even at high temperatures, between oxidized and reduced forms of carbon. And it is reasonable to assume that isotopic exchange of carbon takes place only during chemical reactions. This would make it possible to produce large fractionations by means of a Rayleigh process.

I shall take the usual expression of the Rayleigh law $R=R_{0}$ $f^{\alpha-1}$ where $R$ and $R_{0}$ are the actual and initial isotopic ratios of the oxidized forms, $f$ the fraction left and $\alpha$ the fractionation factor between oxidized and reduced form.

For carbonaceous chondrites the oxidized form is trapped as carbonate and the reduced form consists chiefly of an "aromatic polymer". Isotopic exchange between these two forms without chemical changes is difficult. So the isotopic composition of the two phases may be related through a Rayleigh process. Fractionation factors (Table 1) have been calculated from the results of ref. 3. The agreement between the Ivuna and Orgueil meteorites is good. The as of the type II chondrites are more variable, however, and give an average value of $1.016 \pm 001$. If we assume that the $\mathrm{CH}_{4}$ was formed initially during the reduction process and then trapped as the aromatic compound, we may calculate temperatures for the redox process, from the data of ref. 9 . These give a temperature of $325^{\circ} \mathrm{C}$ for type I chondrites and of $450^{\circ} \mathrm{C}$ for type II.

There are no total carbon values available for the mica

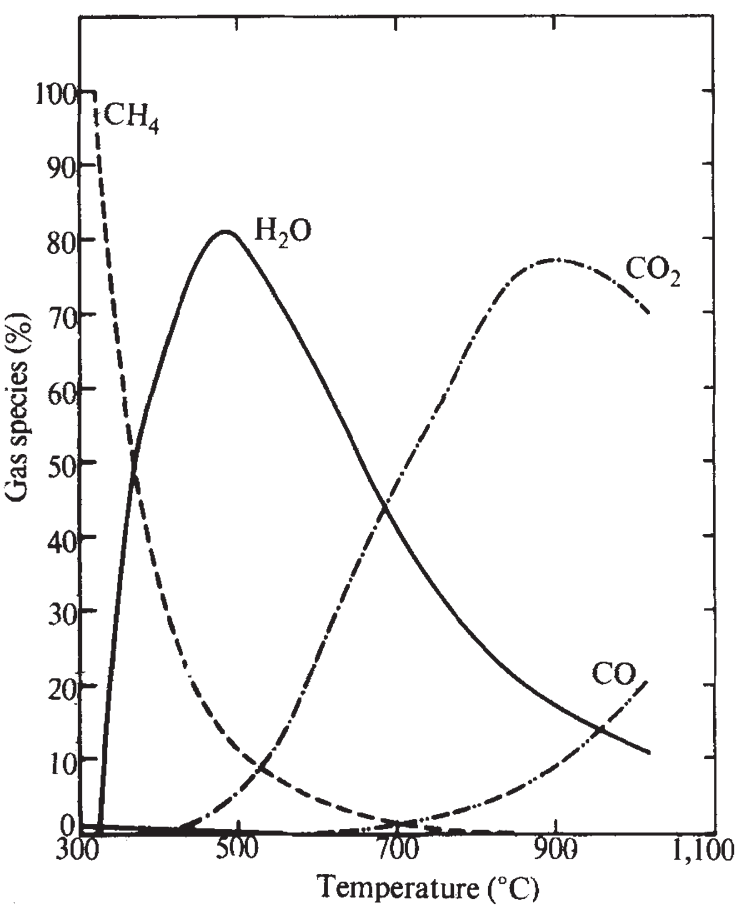

Fig. 1 Relative proportions in the gas phase in the presence of the quartz-magnetite-fayalite buffer (after Eugster and Skippen $^{7}$ ).

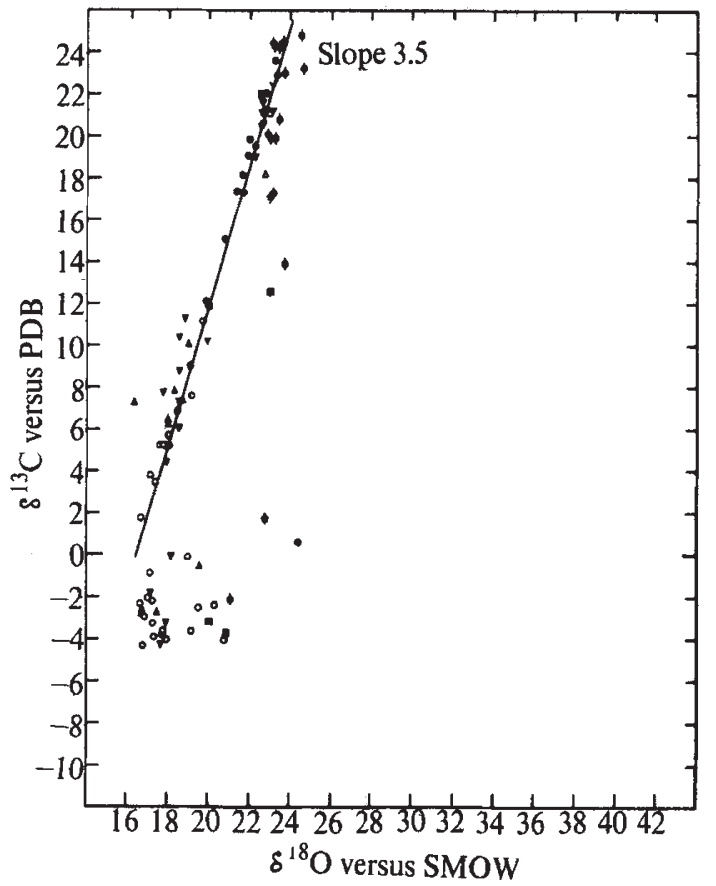

Fig. $2 \delta^{13} \mathrm{C}-\delta^{18} \mathrm{O}$ plot of carbonates from Dixonville (after Deines ${ }^{4}$.

Table 1 Calculation of $\alpha$ after a Rayleigh Distillation Mode $\left(R=R_{0} f^{-1}\right)$ using the Data of Smith and Kaplan ${ }^{3}$

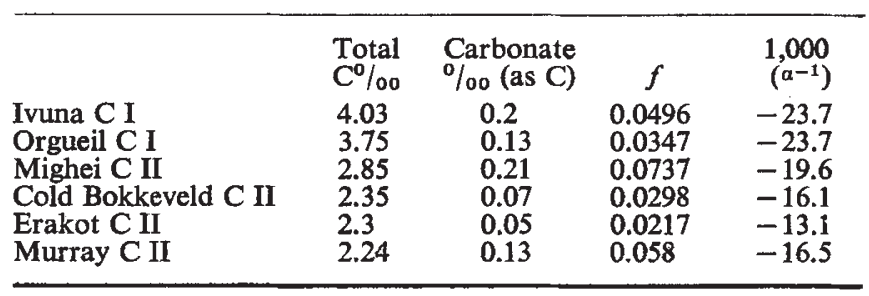

peridotite of Dixonville, so that similar calculations are impossible in this case. But the redox process can be imagined as the reduction of $\mathrm{CO}_{2}$, either primary or resulting from the decomposition of pre-existing carbonates, with the residual $\mathrm{CO}_{2}$ being trapped again as carbonate at different steps of the redox reaction. In this case the slope of the straight line in the $\delta^{13} \mathrm{C}-\delta^{18} \mathrm{O}$ diagram ${ }^{4}$ gives the ratio

$$
\frac{\alpha^{13} \mathrm{C}-1}{\alpha^{18} \mathrm{O}-1}
$$

for this reaction. A reaction such as $\mathrm{CO}_{2}+4 \mathrm{H}_{2} \rightleftharpoons \mathrm{CH}_{4}+$ $2 \mathrm{H}_{2} \mathrm{O}$ would correspond 8,9 to a temperature of $700^{\circ} \mathrm{C}$. The isotopic composition of the original material can be estimated from the origin of the straight line; it is similar to that of metamorphic limestones.

I thank H. Craig for comments and Y. Bottinga for criticism and advice.

Institut de Physique du Globe,

MARC JAVOX

Faculte des Sciences de Paris, 9 Quai Saint-Bernard, Paris 5

Received October 22; revised December 6, 1971.

1 Clayton, R. N., Science, 140, 192 (1963).

2 Krouse, H. R., and Modzeleski, V. E., Geochim. Cosmochim. Acta, 34, 459 (1970).

3 Smith, J. W., and Kaplan, I. R., Science, 167, 1367 (1970).

4 Deines, P., Geochim. Cosmochim. Acta, 32, 613 (1968).

5 Taylor, jun., H. P., Contr. Mineral. Petrol., 19, 1 (1968).

6 Lancet, N. S., and Anders, E., Science, 170, 980 (1970).

7 Eugster, H. P., and Skippen, G. B., Researches in Geochemistry, 492 (Wiley, New York, 1967).

${ }^{8}$ Bottinga, Y., J. Phys. Chem., 72, 800 (1968)

9 Bottinga, Y., Geochim. Cosmochim. Acta, 33, 49 (1969). 